\title{
CULTIVARES DE TRIGO RESPONDEM DIFERENTEMENTE À QUALIDADE DA LUZ QUANTO À EMISSÃO DE AFILHOS E ACUMULAÇÃO DE MASSA SECA
}

\author{
WHEAT CULTIVARS TILLER EMISSION AND DRY MASS ACCUMULATION REACT \\ DIFFERENTLY TO LIGHT QUALITY
}

\section{Milton Luiz de Almeida ${ }^{1}$ Luís Sangoi $^{2}$ Paulo Sérgio Trentin ${ }^{3}$ Jonatan Gálio $^{3}$}

RESUMO

\begin{abstract}
Um experimento foi conduzido com o objetivo de avaliar os efeitos da qualidade da luz, através da suplementação com luz vermelha $(V)$ e luz vermelha extrema (Ve), na emissão de afilhos, na acumulação de massa seca (MS) e na relação do tamanho das primeiras folhas do colmo principal $(C P)$ com a emissão de afilhos em cultivares de trigo. Ele foi conduzido em Lages, SC, em caixas de madeira preenchidas com solo mineral, em ambiente com radiação solar natural. A suplementação com luz V e luz Ve foi feita entre a emissão da terceira e da quarta folha do CP. $O$ experimento foi colhido no final do afilhamento. A cultivar Embrapa 16 aumentou a emissão do afilho do nó da primeira folha (A1) e não modificou a emissão dos afilhos do nó da segunda (A2) e terceira folha (A3) quando foi suplementada com luz $V$. Na cultivar OR1, a suplementação com luz Ve diminuiu a emissão do A1 e A2, enquanto nas cultivares Fundacep 29 e Embrapa 40, a emissão do Al não foi afetada pela suplementação luminosa. A acumulação de MS nos afilhos e a correlação entre emissão de afilhos e parâmetros de crescimento inicial também variaram com as cultivares utilizadas.
\end{abstract}

Palavras-chave: massa seca, luz vermelha, luz vermelha extrema.

\section{SUMMARY}

This trial was conducted aiming to evaluate the effects of light quality, through red $(R)$ and far red (FR) light supplementation, on tiller emission, dry mass accumulation and the relationship between the size of the first main stem leaves with tiller emission, of four wheat cultivars. The experiment was carried out in Lages, SC, using wood boxes filled with mineral soil in an environment with natural radiation. Red and far red light supplementation was imposed between the emission of the third and fourth leaf on the main stem. The trial was harvested at the end of the tillering period. Th e supplementation of red light on cultivar Embrapa 16 enhanced the emission Al and did not affect the production of A2 and A3. Conversely, for cultivar OR1 the supplementation with FR decreased the emission of $A 1$ and $A 2$ whereas cultivars Fundacep 29 and Embrapa 40 did not alter A1 production due to light supplementation. Tiller dry mass accumulation and the correlation between tiller emission and early growth parameters also varied according to the cultivar analyzed.

Key words: dry matter accumulation, light quality

\section{INTRODUÇÃO}

A relação entre a radiação vermelha $(\mathrm{V})$ e a radiação vermelha extrema (Ve) atua como um sinal precoce da competição no desenvolvimento de uma comunidade de plantas, antes mesmo da ocorrência de qualquer redução na radiação fotossinteticamente ativa (SMITH \& HOLMES, 1977). A detecção da relação entre a luz V e a luz Ve é feita pelo fitocromo, que transfere a excitação eletrônica causada pela luz em sinal celular e, através de uma variedade de vias de tradução, altera o metabolismo celular e influencia o

\footnotetext{
${ }^{1}$ Engenheiro Agrônomo, Doutor, Bolsista do CNPq, Professor do Curso de Agronomia da Universidade do Estado de Santa Catarina (UDESC), CP 281, 88520-000, Lages, SC. E-mail: milton@cav.udesc.br. Autor para correspondência.

${ }^{2}$ Engenheiro Agrônomo, PhD., Professor do Curso de Agronomia da UDESC. Bolsista do CNPq.

${ }^{3}$ Acadêmico do Curso de Agronomia da UDESC, bolsista de Iniciação Científica do CNPq.

Recebido para publicação em 09.04.01. Aprovado em 22.08.01
} 
desenvolvimento das plantas (BALLARÉ et $\boldsymbol{a l}$., 1987). Esse comportamento é uma resposta adaptativa ao sombreamento, sendo as plântulas jovens especialmente aptas a detectarem a baixa relação V:Ve (BALLARÉ $\boldsymbol{e t}$ al., 1997; SCHMITT, 1997).

Um dos motivos da baixa produtividade média das lavouras de trigo no Brasil é a pequena participação dos afilhos na formação do rendimento final (MEROTTO JUNIOR, 1995; ALMEIDA, 1998; MUNDSTOCK, 1999). A emissão, o desenvolvimento e a sobrevivência dos afilhos são importantes, pois estas estruturas fazem parte dos componentes de rendimento e são também supridoras de assimilados ao colmo principal (LAUER \& SIMMONS, 1988; MEROTTO JUNIOR, 1995). O número de afilhos emitidos depende de fatores ligados ao genótipo e ao ambiente.

Além de sua emissão, é fundamental que se identifiquem os fatores responsáveis pela maior sobrevivência dos afilhos. Nesse sentido, GAUTIER et al. (1999) afirmam que a relação entre a luz vermelha $(V)$ e a luz vermelha extrema (Ve) é o sinal do ambiente mais importante para o afilhamento. A compreensão de como o processo de afilhamento interage com a luz é importante porque a partir desse conhecimento pode-se alterar a sensibilidade das plantas a determinados comprimentos de onda. BALLARÉ et al. (1997) acreditam que a superexpressão do fitocromo A, em níveis moderados, pode ser um caminho potencialmente interessante a ser desenvolvido, visando à obtenção de plantas que melhor explorem os recursos disponíveis do ambiente.

Em estudos realizados com cultivar de trigo Embrapa 16, ALMEIDA (1998) verificou que o afilhamento dessa cultivar foi afetado pela suplementação com luz V e Ve. A suplementação com luz V aumentou a emissão de afilhos, a acumulação de massa seca (MS) nos afilhos e proporcionou maior equilíbrio na distribuição de MS entre afilhos e o colmo principal. Posteriormente, na mesma cultivar, trabalhando com suplementação com luz V e Ve, ALMEIDA et al. (2000b) detectaram que a definição da emissão dos afilhos ocorreu até a emissão da quarta folha, o que indica que a decisão quanto à emissão de afilhos ocorreu muito precocemente para esta cultivar.

Ao trabalharem com diferentes cultivares de azevém, GAUTIER et al. (1999) verificaram que poderiam apresentar um padrão de comportamento para azevém, já que para todas as cultivares testadas, havia correlação negativa entre taxa de elongação foliar e taxa de emissão de afilhos. Para trigo,
ALMEIDA (1998) e ALMEIDA et al. (2000b) trabalharam apenas com a cultivar Embrapa 16, em que os autores verificaram que a maior disponibilidade de luz vermelha determinou maior emissão de afilhos e afilhos com maior MS. No entanto, somente esses trabalhos não são suficientes para determinar o padrão de comportamento da espécie, já que as bases genéticas entre cultivares são distintas. Portanto, a verificação desse comportamento é importante antes do início de qualquer trabalho que vise a mudança da sensibilidade de trigo à qualidade da luz.

O presente experimento foi conduzido com o objetivo de verificar os efeitos da qualidade da luz, ou seja da suplementação com luz V e luz Ve, em diferentes cultivares de trigo na emissão de afilhos e na sua acumulação de MS. Além disso, objetivou-se verificar a correlação entre o acúmulo de MS das quatro primeiras folhas do colmo principal e a emissão de afilhos.

\section{MATERIAL E MÉTODOS}

$\mathrm{O}$ experimento foi conduzido no município de Lages, SC, localizado no Planalto Sul de Santa Catarina (latitude: 27'52'S"; longitude: $50^{\circ} 18^{\prime} \mathrm{W}$ e altitude média de 930 metros. As plantas foram cultivadas em caixas de madeira quadradas, com $1,2 \mathrm{~m}$ de lado e $0,30 \mathrm{~m}$ de altura. As caixas foram preenchidas com solo mineral que apresentava as seguintes características: $47 \%$ de argila; 5,1 de $\mathrm{pH}$ (em água); 2,5mg. $\mathrm{kg}^{-1}$ de $\mathrm{P}$, $52 \mathrm{mg} \cdot \mathrm{kg}^{-1}$ de $\mathrm{K}, 31 \mathrm{~g} \cdot \mathrm{kg}^{-1}$ de matéria orgânica, $3,8 \mathrm{cmo} \ell_{\mathrm{c}} \cdot \mathrm{kg}^{-1}$ de $\mathrm{A} \ell, 2,4 \mathrm{cmo} \ell_{\mathrm{c}} \cdot \mathrm{kg}^{-1}$ de $\mathrm{Ca}+\mathrm{Mg}$. Este solo foi corrigido antecipadamente a instalação do experimento com uma dose de 7,5t.ha ${ }^{-1}$ de calcário, $60 \mathrm{~kg} \cdot \mathrm{ha}^{-1}$ de $\mathrm{K}_{2} \mathrm{O}$ e $80 \mathrm{~kg} \cdot \mathrm{ha}^{-1}$ de $\mathrm{P}_{2} \mathrm{O}_{5}$, considerando uma camada de $30 \mathrm{~cm}$ de solo. Após a realização do experimento, uma análise parcial de solo detectou os seguintes valores: 5,25 de $\mathrm{pH}$ (em água), 20,6 mg.kg-1 de P; $125 \mathrm{mg} . \mathrm{kg}^{-1}$ de K; sem a presença de A $\ell$ tóxico.

O experimento foi instalado com sementes pré-germinadas em 01 de setembro de 1999. A pré-germinação foi realizada a uma temperatura aproximada de $23^{\circ} \mathrm{C}$ e $100 \%$ de umidade relativa do ar. As plântulas, apresentando a protusão da radícula, foram plantadas utilizando-se pinça e régua. Os espaçamentos utilizados foram $1,7 \mathrm{~cm}$ entre plântulas e $20 \mathrm{~cm}$ entre linhas proporcionando uma densidade de 294 plântulas por metro quadrado. Foram plantadas em cada caixa seis linhas, orientadas no sentido norte-sul, sendo consideradas cada uma das quatro linhas centrais uma repetição. A emergência da primeira folha ocorreu três dias após a semeadura. 
O delineamento experimental utilizado foi o completamente casualizado num esquema fatorial $4 \times 3$. Os tratamentos consistiram de quatro cultivares de trigo (OR1, Fundacep 29, Embrapa 16 e Embrapa 40) que foram suplementadas das 7:00 às 18:00 horas com luz vermelha, com luz vermelha extrema e mais uma testemunha por cultivar. A suplementação com luz foi iniciada na emissão da terceira folha e encerrada na emissão da quarta folha do colmo principal. Para as cultivares Embrapa 16 e Embrapa 40, isto ocorreu no dia 16/09/99 e, para as cultivares OR1 e Fundacep 29, no dia 17/09//99. A retirada da suplementação foi em 22/09/99, para todas as cultivares.

A luz vermelha foi adicionada através da conjugação de duas lâmpadas fluorescentes de $20 \mathrm{~W}$, acopladas numa calha de $1,0 \mathrm{~m}$ de comprimento e duas folhas de celofane vermelho, colocadas imediatamente abaixo das lâmpadas. A calha de lâmpadas foi colocada transversalmente ao sentido das linhas das plantas a $40 \mathrm{~cm}$ acima delas. A luz vermelha extrema foi obtida através de dois conjuntos, cada qual com uma lâmpada incandescente de 40W, acoplada em um holofote de $22 \mathrm{~cm}$ de diâmetro, com duas folhas de celofane azul e duas folhas de celofane vermelho, colocadas imediatamente abaixo da lâmpada. Os dois conjuntos foram colocados a $40 \mathrm{~cm}$ acima das linhas de cultivo, sendo um colocado sobre as linhas de número 2 e 3 e o outro sobre as linhas 4 e 5 . Conforme determinações feitas por CARDOSO (1995) estes conjuntos proporcionam aproximadamente $0,012 \mathrm{~W} \cdot \mathrm{m}^{-2} \cdot \mathrm{nm}^{-1}$, o que equivale a uma densidade de fluxo de fótons de $0,055 \mu \mathrm{mo} \ell . \mathrm{m}^{-2} \cdot \mathrm{s}^{-1}$ e $0,060 \mu \mathrm{mo} \ell . \mathrm{m}^{-2} . \mathrm{s}^{-1}$, de luz V e Ve respectivamente, conforme transformação proposta por THIMIJAN \& HEINS (1983). Nos dois tipos de suplementação, o celofane foi substituído à medida que havia diminuição de sua coloração.

O desenvolvimento foliar (número de folhas) foi avaliado através da escala proposta por HAUN (1973). Esta escala descreve o colmo principal e os afilhos separadamente e baseia-se na notação decimal do crescimento das folhas. A denominação de folhas e afilhos foi adaptada do padrão utilizado por MASLE (1985). O afilhos foram denominados pela letra $\mathrm{A}$, seguido do número da folha de cujo nó são originados. Dessa forma tem-se o seguinte resultado: A0 - afilho originado do nó do coleoptile; A1 - afilho originado do nó da primeira folha do colmo principal; A1.1 - afilho originado do nó da primeira folha do A1; An - afilho originado do nó da enésima folha do colmo principal.

As plantas daninhas, pragas e doenças foram controladas. A coleta das plantas foi realizada
53 dias após a emergência, no estádio 7,5 da escala Haun. Coletaram-se 20 plantas em cada repetição, as quais estavam localizadas embaixo das lâmpadas, mas não eram sombreadas pelas mesmas. Após a coleta, estas plantas foram separadas em colmo principal e afilhos, sendo os afilhos de ordem mais elevada agrupados com os afilhos primários das mesmas folhas (ex.: A1.1 junto com o A1). Após a separação, o colmo principal e os afilhos foram colocados separadamente em sacos de papel para secagem em estufa de fluxo de ar contínuo, a aproximadamente $60^{\circ} \mathrm{C}$, até massa constante. Foram realizadas as seguintes determinações:

- \% de afilhos emitidos = percentual de plantas com a presença de cada um dos afilhos primários analisados;

- massa seca dos afilhos emitidos e massa seca total dos afilhos (somatório da massa de todos os afilhos);

- massa seca do colmo principal;

- massa seca das quatro primeiras folhas do colmo principal;

Os dados do experimento foram analisados estatisticamente através da técnica da análise da variância. Quando alcançada significância estatística, as médias foram comparadas pelo teste de DMS ao nível de significância de 5\%. Realizouse análise de correlação simples, para cada cultivar, entre percentagem de emissão de afilhos e MS das primeiras folhas, MS do CP e MS de toda a planta.

\section{RESULTADOS E DISCUSSÃO}

A suplementação com luz $\mathrm{V}$ e luz Ve interagiu com as cultivares na maioria das avaliações realizadas, com exceção da percentagem de emissão do afilho A3 e da MS do afilho A2. Esses resultados indicam que as cultivares responderam diferentemente à suplementação luminosa, o que pode ser observado, na análise individual de cada cultivar.

A cultivar Embrapa 16 emitiu um maior número de afilhos do nó da primeira folha (A1) quando foi suplementada com luz $\mathrm{V}$, enquanto que não modificou a emissão dos afilhos do nó da segunda (A2) e da terceira (A3) folha (Tabela 1). Esses resultados estão de acordo aos resultados obtidos por ALMEIDA (1998), ALMEIDA et al. (2000a) e ALMEIDA et al. (2000b). A suplementação luminosa na cultivar OR1 proporcionou resultado diferenciando, ou seja, a suplementação com luz Ve diminuiu a emissão do afilho A1, enquanto a emissão do afilho A2 foi diminuída, tanto pela luz V como Ve (Tabela 1). Na cultivar Fundacep 29, que apresentou menor emissão 
Tabela 1 - Percentagem de afilhos emitidos e massa seca acumulada por afilho em 20 plantas amostradas de quatro cultivares de trigo em função da aplicação de luz vermelha (V) e luz vermelha extrema (Ve). Lages, SC, 1999.

\begin{tabular}{|c|c|c|c|c|c|c|c|}
\hline \multicolumn{5}{|c|}{ Percentagem de emissão do afilho A1** } & \multicolumn{3}{|c|}{ Percentagem de emissão do afilho A2*** } \\
\hline Cultivares & $\mathrm{V}$ & $\mathrm{Ve}$ & Testemunha & & $\mathrm{V}$ & $\mathrm{Ve}$ & Testemunha \\
\hline OR1 & A $67,50 b^{*}$ & B $33,75 \mathrm{~b}$ & A $76,75 a$ & & B $25,00 b$ & B $21,25 b$ & A $53,25 b$ \\
\hline FUND 29 & A $7,50 \mathrm{~d}$ & A $18,75 b c$ & A $6,25 \mathrm{~d}$ & & B $3,75 b$ & A $27,50 b$ & B $1,25 \mathrm{c}$ \\
\hline EMB 16 & A $87,50 a$ & B $6,50 \mathrm{c}$ & B $5,00 \mathrm{c}$ & & A $71,25 \mathrm{a}$ & A $79,75 a$ & A $82,50 a$ \\
\hline EMB 40 & A $45,00 \mathrm{c}$ & A $57,00 \mathrm{a}$ & A $51,25 b$ & & B $8,75 b$ & A $38,25 b$ & A $43,75 b$ \\
\hline \multicolumn{5}{|c|}{ Percentagem de emissão do afilho A3**** } & \multicolumn{3}{|c|}{ Massa seca do afilho A1 (g) } \\
\hline Cultivares & $\mathrm{V}$ & $\mathrm{Ve}$ & Testemunha & Médias & $\mathrm{V}$ & $\mathrm{Ve}$ & Testemunha \\
\hline OR1 & 3,75 & 5,00 & 13,25 & $7,33 b$ & A $1,01 b$ & B $0,34 b$ & A $1,17 \mathrm{a}$ \\
\hline FUND 29 & 8,75 & 2,50 & 0,00 & $3,75 b$ & A $0,11 \mathrm{c}$ & A $0,27 b$ & A $0,06 \mathrm{c}$ \\
\hline EMB 16 & 26,25 & 49,75 & 36,25 & $37,42 \mathrm{a}$ & A $2,09 a$ & B $0,23 b$ & B $0,54 b$ \\
\hline EMB 40 & 0,00 & 3,75 & 1,25 & $1,67 b$ & B $0,64 b$ & A $1,18 \mathrm{a}$ & A $1,05 \mathrm{a}$ \\
\hline \multicolumn{5}{|c|}{ Massa seca do afilho A2 (g) } & Massa & \multicolumn{2}{|c|}{ seca do afilho A3 (g) } \\
\hline Cultivares & $\mathrm{V}$ & $\mathrm{Ve}$ & Testemunha & Médias & $\mathrm{V}$ & $\mathrm{Ve}$ & Testemunha \\
\hline OR1 & 0,45 & 0,19 & 0,70 & $0,45 b$ & A $0.02 b$ & A $0,01 b$ & A $0,09 b$ \\
\hline FUND 29 & 0,02 & 0,27 & 0,01 & $0,10 \mathrm{c}$ & A $0,10 b$ & A $0,02 b$ & A $0,00 b$ \\
\hline EMB 16 & 1,42 & 1,60 & 1,70 & $1,57 \mathrm{a}$ & В $0,39 a$ & A $0,91 \mathrm{a}$ & B $0,47 a$ \\
\hline EMB 40 & 0,05 & 0,47 & 0,36 & $0,29 b c$ & A $0,00 \mathrm{~b}$ & A $0,03 \mathrm{~b}$ & A $0,00 \mathrm{~b}$ \\
\hline
\end{tabular}

* médias seguidas pela mesma letra minúscula na vertical e pela mesma letra maiúscula na horizontal não diferem estatisticamente pelo teste DMS, ao nível de significância de 5\%.

** A1 = afilho do nó da primeira folha.

***A2 = afilho do nó da segunda folha

****A3 = afilho do nó da terceira folha.

de afilhos, a emissão do afilho A1 não foi afetada pela suplementação luminosa, enquanto a suplementação com luz Ve aumentou a emissão do afilho A2 (Tabela 1). Para a cultivar Embrapa 40, os resultados também foram diferenciados, ou seja, a emissão do afilho A1 não foi afetada pela suplementação luminosa, enquanto a emissão do afilho A2 foi menor quando da suplementação com luz V (Tabela 1).

A variação de comportamento apresentado pelas cultivares em função da suplementação com luz $\mathrm{V}$ e Ve não segue o comportamento até então identificado para a cultivar Embrapa 16. Para essa cultivar, ALMEIDA (1998) e ALMEIDA et al.(2000a) verificaram que a suplementação com luz $\mathrm{V}$ aumentou a emissão de afilhos. Nesses trabalhos, os autores concluíram que a maior disponibilidade de luz vermelha, detectada precocemente pelas plantas, induziu a maior emissão de afilhos em função da menor dominância apical do colmo principal sobre os afilhos, o que também foi sugerido por BALLARÉ $\boldsymbol{e t}$ al. (1992) e SCHMITT \& WULFF (1993). Alguns motivos para a resposta diferencial das cultivares à qualidade da luz podem ser apresentados. Para a cultivar Fundacep 29, o motivo pode ter sido o baixo afilhamento apresentado (Tabela 1), ou seja, para essa cultivar outros fatores limitaram mais acentuadamente a emissão de afilhos do que a qualidade da luz. O mesmo não pode ser afirmado para a cultivar Embrapa 40, que apresentou maior emissão de afilhos sendo que a luz vermelha claramente inibiu a emissão do afilho A2 (Tabela 1). Também para as cultivares OR1 e Embrapa 16, os mecanismos de resposta foram diferenciados, embora tenham apresentado coerência quanto aos efeitos esperados da qualidade da luz. Para a cultivar OR1, o efeito mais marcante foi o da luz Ve, que inibiu a emissão de afilhos, principalmente do A1. Já para a cultivar Embrapa 16, a luz V determinou maior emissão de afilhos. O comportamento dessas duas cultivares se enquadra dentro de um padrão esperado dos efeitos da qualidade da luz. Isto porque a maior disponibilidade de luz $\mathrm{V}$ é detectada pelas plantas como um ambiente de menor competição, o que resulta em maior emissão de afilhos. Por outro lado, a maior disponibilidade de luz Ve é detectada pelas plantas como um ambiente de maior competição, o que resulta em menor emissão de afilhos.

A acumulação de massa seca nos afilhos também variou conforme a cultivar utilizada. O acúmulo de MS, no afilho A1, foi semelhante ao resultado da emissão desse afilho, enquanto que para o afilho A2 não foi detectada diferença estatística (Tabela 1). A análise da massa seca acumulada pelos afilhos é tão importante quanto a emissão, isso porque para que um afilho sobreviva, a primeira condição é que a sua taxa de crescimento seja similar à do colmo principal (WOBETO, 1994). Nesse sentido, para as duas cultivares de maior emissão de afilhos, OR1 e Embrapa 16, verificou-se maior massa seca do afilho A1 nos tratamentos com luz V. Isso mostra que um ambiente de maior disponibilidade de luz $\mathrm{V}$, ou seja, de menor 
competição, detectado pelas plantas antes da competição por quantidade de luz, pode ser importante para aumentar a participação de afilhos no rendimento de grãos.

Em termos de acúmulo de massa, o comportamento apresentado pelo colmo principal (CP) é importante para determinar a dominância dessa estrutura sobre os afilhos. A cultivar Embrapa 16 apresentou menor acúmulo de $\mathrm{MS}$ no $\mathrm{CP}$ no tratamento com luz V (Tabela 2), exatamente o tratamento que permitiu maior emissão de afilhos para essa cultivar (Tabela 1). Já as cultivares Fundacep 29 e Embrapa 40 foram as que apresentaram maior acúmulo de MS no CP (Tabela 2) e também foram as que apresentaram a menor emissão de afilhos (Tabela 1). Em um estudo com 10 cultivares de trigo, VAN DE BOOGAARD $\boldsymbol{e t} \boldsymbol{a l}$. (1997) também identificaram grande variação de alocação de MS entre as cultivares.

$\mathrm{O}$ efeito diferencial entre cultivares da dominância do colmo principal (CP) sobre os afilhos também pôde ser avaliado quando da comparação de acúmulo de MS nos afilhos e nas quatro primeiras folhas do CP (Tabela 2). As cultivares OR 1 e Embrapa 16 apresentaram maior acúmulo de MS nos afilhos quando da suplementação com luz V, enquanto a cultivar Fundacep 29 apresentou mesmo padrão de acúmulo nos três tratamentos (Tabela 2). Já para a cultivar Embrapa 40, o maior acúmulo de MS nos afilhos foi identificado no tratamento com luz Ve. Para a MS nas quatro primeiras folhas do
$\mathrm{CP}$, novamente para as cultivares OR 1 e Embrapa 16, a suplementação com luz $\mathrm{V}$ determinou maior acúmulo, enquanto para as outras duas cultivares não houve diferença entre os tratamentos (Tabela 2).

Análise de correlação simples entre variáveis de crescimento inicial e a emissão de afilhos, individualizada para cada cultivar, também detectou comportamento diferenciado entre as cultivares. Para a cultivar Embrapa 16, identificouse correlação significativa positiva entre o acúmulo de MS nas quatro primeiras folhas e MS em toda a planta com a percentagem de emissão do afilho A1 (Tabela 3). Esses resultados estão de acordo com os obtidos por SKINNER \& NELSON (1995) que observaram que maior crescimento foliar esteve correlacionado com o aparecimento de novas folhas e afilhos. Para essa cultivar, não se identificou correlação entre percentagem de emissão do A1 e MS do CP. Isso possivelmente se deva à dominância apical que o CP dessa cultivar exerce sobre esse afilho, fato também observado por ALMEIDA (1998) e ALMEIDA et al. (2000a). Para a cultivar OR1, a emissão do afilho A1 esteve correlacionada positivamente com as três variáveis de crescimento inicial, inclusive com a MS do CP (Tabela 3). Este comportamento demonstra que, para essa cultivar, a dominância do CP não afetou a emissão do A1. Por outro lado, para as cultivares Fundacep 29 e Embrapa 40 não se identificou correlação entre os parâmetros de crescimento inicial e a percentagem de emissão do afilho A1 (Tabela 3).

Para o afilho A2, o estudo

Tabela 2 - Massa seca acumulada no colmo principal, em todos os afilhos e nas quatro primeiras folhas do colmo principal em 20 plantas amostradas, de quatro cultivares de trigo, em função da aplicação de luz vermelha (V) e luz vermelha extrema (Ve). Lages, SC, 1999.

\begin{tabular}{lcccccc}
\hline \multicolumn{1}{l}{ Massa seca do colmo principal (g) } & \multicolumn{4}{c}{ Massa seca dos afilhos (g) } \\
\hline Cultivares & V & Ve & Testemunha & V & Ve & Testemunha \\
OR1 & B 4,85bc* & C 3,53c & A 6,48b & A 1,52b & B 0,56c & A 1,98ab \\
FUND 29 & A 5,96ab & AB 5,71b & B 4,45c & A 0,25c & A 0,56c & A 0,07c \\
EMB 16 & A 4,07c & A 3,82c & A 3,74c & A 3,91a & B 2,85a & B 2,71a \\
EMB 40 & B 7,23a & A 8,52a & A 9.72a & B 0,69c & A 1,68b & AB 1,41b \\
\multicolumn{4}{c}{ Massa seca das quatro primeiras folhas do colmo principal (g) } \\
Cultivares & \multicolumn{2}{c}{ V } & Ve & Testemunha \\
OR1 & A 1,04b & B 0,82c & A 1,06b \\
FUND 29 & A 1,09b & A 1,00b & A 0,98b \\
EMB 16 & A 1,27a & B 0,90bc & B 1,03b \\
EMB 40 & A 1,25a & A 1,23a & A 1,27 \\
\hline
\end{tabular}

* médias seguidas pela mesma letra minúscula na vertical e pela mesma letra maiúscula na horizontal não diferem estatisticamente pelo teste DMS, ao nível de significância de $5 \%$. de correlação entre variáveis do crescimento inicial e a percentagem de emissão desse afilho identificou comportamento diferente do constatado para o afilho A1. Nas cultivares OR1, Fundacep 29 e Embrapa 40 a emissão do A2 se correlacionou com o acúmulo de MS no CP e em todo a planta (Tabela 3). Diferentemente disso, para a cultivar Embrapa 16 não se identificou correlação entre a percentagem de emissão do A2 e as variáveis de crescimento inicial. Essa ausência de correlação, possivelmente justifique a constatação de ALMEIDA (1998) e ALMEIDA $\boldsymbol{e t}$ al. (2000a) de que a emissão do afilho A2 é menos sensível a fatores do meio.

Através desses resultados, verifica-se que também no estudo de 
Tabela 3 - Coeficientes de correlação simples (r) entre a percentagem de emissão de afilhos e três variáveis de acumulação de massa seca (MS) de quatro cultivares de trigo em função da aplicação de luz vermelha e luz vermelha extrema. Lages, SC, 1999.

\begin{tabular}{|c|c|c|c|c|}
\hline Cultivar & Variáveis & $\begin{array}{l}\% \text { de emissão } \\
\text { do afilho A1 }\end{array}$ & $\begin{array}{l}\% \text { de emissão } \\
\text { do afilho } \mathrm{A} 2\end{array}$ & $\begin{array}{l}\% \text { de emissão } \\
\text { do afilho A3 }\end{array}$ \\
\hline \multirow{3}{*}{ OR1 } & MS do colmo principal & $\mathrm{r}=0,76^{* *}$ & $\mathrm{r}=0,74 * *$ & $\mathrm{r}=0,48 \mathrm{~ns}$ \\
\hline & $\begin{array}{l}\text { MS das quatro primeiras } \\
\text { folhas do colmo principal }\end{array}$ & $\mathrm{r}=0,91 * *$ & $\mathrm{r}=0,39 \mathrm{~ns}$ & $\mathrm{r}=0,19 \mathrm{~ns}$ \\
\hline & MS de toda a planta & $\mathrm{r}=0,84 * *$ & $\mathrm{r}=0,77 * *$ & $\mathrm{r}=0,53 \mathrm{~ns}$ \\
\hline Cultivar & Variáveis & $\begin{array}{l}\% \text { de emissão } \\
\text { do afilho A1 }\end{array}$ & $\begin{array}{l}\% \text { de emissão } \\
\text { do afilho A2 }\end{array}$ & $\begin{array}{l}\% \text { de emissão } \\
\text { do afilho A3 }\end{array}$ \\
\hline \multirow{3}{*}{ Fundacep 29} & MS do colmo principal & $\mathrm{r}=0,42 \mathrm{~ns}$ & $\mathrm{r}=0,62 *$ & $\mathrm{r}=0,41 \mathrm{~ns}$ \\
\hline & $\begin{array}{l}\text { MS das quatro primeiras } \\
\text { folhas do colmo principal }\end{array}$ & $r=-0,18 n s$ & $\mathrm{r}=0,17 \mathrm{~ns}$ & $\mathrm{r}=0,23 \mathrm{~ns}$ \\
\hline & MS de toda a planta & $\mathrm{r}=0,52 \mathrm{~ns}$ & $r=0,68 *$ & $\mathrm{r}=0,40 \mathrm{~ns}$ \\
\hline Cultivar & Variáveis & $\begin{array}{l}\% \text { de emissão } \\
\text { do afilho A1 }\end{array}$ & $\begin{array}{l}\% \text { de emissão } \\
\text { do afilho A2 }\end{array}$ & $\begin{array}{l}\% \text { de emissão } \\
\text { do afilho A3 }\end{array}$ \\
\hline \multirow{3}{*}{ EMBRAPA 16} & MS do colmo principal & $\mathrm{r}=0,29 \mathrm{~ns}$ & $\mathrm{r}=0,16 \mathrm{~ns}$ & $\mathrm{r}=0,48 \mathrm{~ns}$ \\
\hline & $\begin{array}{l}\text { MS das quatro primeiras } \\
\text { folhas do colmo principal }\end{array}$ & $r=0,84 * *$ & $\mathrm{r}=-0,31 \mathrm{~ns}$ & $\mathrm{r}=-0,50 \mathrm{~ns}$ \\
\hline & MS de toda a planta & $r=0,61 *$ & $\mathrm{r}=0,14 \mathrm{~ns}$ & $\mathrm{r}=0,32 \mathrm{~ns}$ \\
\hline Cultivar & Variáveis & $\begin{array}{l}\% \text { de emissão } \\
\text { do afilho A1 }\end{array}$ & $\begin{array}{l}\% \text { de emissão } \\
\text { do afilho A2 }\end{array}$ & $\begin{array}{l}\% \text { de emissão } \\
\text { do afilho A3 }\end{array}$ \\
\hline \multirow{3}{*}{ EMBRAPA 40} & MS do colmo principal & $\mathrm{r}=0,04 \mathrm{~ns}$ & $\mathrm{r}=0,78 * *$ & $r=0,64 *$ \\
\hline & $\begin{array}{l}\text { MS das quatro primeiras } \\
\text { folhas do colmo principal }\end{array}$ & $\mathrm{r}=0,16 \mathrm{~ns}$ & $\mathrm{r}=0,08 \mathrm{~ns}$ & $\mathrm{r}=0,29 \mathrm{~ns}$ \\
\hline & MS de toda a planta & $\mathrm{r}=0,16 \mathrm{~ns}$ & $\mathrm{r}=0,81 * *$ & $r=0,68 *$ \\
\hline
\end{tabular}

* significativo pelo teste t ao nível de significância de 5\%.

** significativo pelo teste t ao nível de significância de $1 \%$.

correlação entre emissão de afilhos e parâmetros de crescimento inicial, as cultivares testadas apresentaram comportamento diferenciado entre si. As modificações na qualidade da luz em uma comunidade de plantas se devem basicamente a absorção diferencial da luz V e Ve pelas plantas. Dessa forma, cultivares que apresentam maior área foliar das primeiras folhas determinariam diminuição mais acentuada da qualidade da luz, pela maior absorção da luz V. As cultivares Embrapa 16 e Embrapa 40 apresentaram o maior acúmulo de MS nas quatro primeiras folhas do colmo principal quando suplementadas com luz V. No entanto, apresentaram resultados contrastantes quanto à emissão de afilhos, principalmente para o afilho A1. A cultivar Embrapa 16 apresentou a maior emissão $(87,5 \%)$ e a cultivar Embrapa 40 a menor emissão (45,0\%). Por sua vez, para azevém GAUTIER $\boldsymbol{e t}$ al. (1999) identificaram, após o corte das plantas, maior emissão de afilhos nas plantas que apresentavam folhas menores. Segundo os autores, isso seria devido à necessidade de maior alocação de carboidratos nas folhas de plantas com folhas mais longas, em detrimento dos afilhos.
Os resultados diferenciados apresentados pelas cultivares mostram que, a resposta das cultivares a suplementação com luz $\mathrm{V}$ e luz $\mathrm{Ve}$ interage de forma diferenciada. Portanto, podese afirmar que, além da modificação da qualidade da luz, determinada pelo crescimento da planta, há interação com fatores fisiológicos e bioquímicos das cultivares, que se refletem na maior ou menor sensibilidade à suplementação com luz V e Ve. CHORY \& LI (1997) afirmam que a luz não age independentemente, mas sim se integrando num programa de desenvolvimento espacial e temporal da ação gênica, do desenvolvimento de organelas e da diferenciação celular. Eles ainda afirmam que esse programa pode incluir a ação de diferentes fitohormônios, embora ainda não se conheça precisamente a interação entre eles e a luz. Nesse mesmo sentido, KRAEPIEL \& MIGINIAC (1997) concluíram que a relação entre luz e fitohormônios é numerosa e extremamente diversificada.

\section{REFERÊNCIAS BIBLIOGRÁFICAS}

ALMEIDA, M.L. de. Modificação do afilhamento de trigo e aveia pela qualidade da luz. Porto Alegre, 1998. 120p. Tese (Doutorado em Fitotecnia) - Programa de Pós-graduação em Agronomia, Faculdade de Agronomia, UFRGS, 1998.

ALMEIDA, M.L. de, MUNDSTOCK, C.M., SANGOI, L. Evocação de afilhos pela qualidade da luz em plantas de trigo cultivadas em diferentes substratos. Revista Brasileira de Fisiologia Vegetal, Londrina, v.12, p.25-36, 2000a.

ALMEIDA, M.L. de, SANGOI, L. ENDER, M, et al. Determinação do momento da emissão de afilhos de trigo usando suplementação com luz vermelha e luz vermelha extrema. Pesquisa Agropecuária Gaúcha, Porto Alegre, v.6, n.1, p.89-97, 2000b .

BALLARÉ, C.L., SÁNCHEZ, R.A., SCOPEL, A.L., et al. Early detection of neighbour plants by phytochrome perception of spectral changes in reflected sunlight. Plant Cell and Environment, Oxford, v.10, p.551-557, 1987.

BALLARÉ, C.L., SCOPEL, A.L., SÁNCHEZ, R.A. Foraging for light: photosensory ecology and agricultural implications. Plant, Cell and Environment, Oxford, v.20, p.820-825, 1997. 
BALLARÉ, C.L., SCOPEL, A.L., SÁNCHEZ, R.A., et al. Photomorphogenic processes in the agricultural environment. Photochemistry and Photobiology, Oxford, v.56, p.777$788,1992$.

CARDOSO, V.J.M. Germinação e fotoblastismo de sementes de Cucumis anguria: influência da qualidade da luz durante a maturação e secagem. Revista Brasileira de Fisiologia Vegetal, Londrina, v.7, p.75-80, 1995.

CHORY, J., LI, J. Gibberellins, brassinosteroids and lightregulated development. Plant, Cell and Environmental, Oxford, v.20, p.801-806, 1997.

GAUTIER, H., GRANCHER, C., HAZARD, I. Tillering responses to the light environment and to defoliation in populations of perennial ryegrass (Lolium perenne L.) selected for contrasting leaf length. Annals of Botany, London, v.83, p.423-429, 1999.

HAUN, J.R. Visual quantification of wheat development. Agronomy Journal, Madison, v.65, p.116-119, 1973.

KRAEPIEL, Y, MIGINIAC, E. Photomorphogenesis and phytohormones. Plant, Cell and Environmental, Oxford, v.20, p.807-812, 1997

LAUER, J.G., SIMMONS, S.R. Photoassimilate partitioning by tillers and individual tiller leaves in field-grown spring barley. Crop Science, Madison, v.28, p.279-282, 1988.

MASLE, J. Competition among tillers in winter wheat: consequences for growth and development of the crops. In NATO ADVANCED RESEARCH WORKSHOP ON WHEAT GROWTH AND MODELLING, 1984, Bristol. Proceeding... New York : Plenum, 1985. p.407. p.33-54 (NATO ASI Serie A, Live Science, v. 86)

MEROTTO JUNIOR, A. Processo de afilhamento e crescimento de raízes de trigo afetados pela resistência do solo. Porto Alegre, 1995. 114p. Dissertação (Mestrado em Fitotecnia) - Programa de Pós-graduação em Agronomia, UFRGS, 1995.

MUNDSTOCK, C.M. Planejamento e manejo integrado da lavoura de trigo. Porto Alegre : Evangraf, 1999. 228p.

SCHMITT, J. Is photomorphogenic shade avoidance adaptive? Perspectives from population biology. Plant, Cell and Environmental, Oxford,v.20, p.826-830, 1997.

SCHMITT, J., WULFF, R.D. Light spectral quality phytochrome and plant competition. Trends in Ecology and Evolution, Victoria, v.8, n.1, p.47-51, 1993.

SMITH, H., HOLMES, M.G. The function of phytochrome in the natural environment. III. Measurements and calculation of phytochrome photoequilibria. Photochemistry and Photobiology, Oxford, v.20, p.457-550, 1977.

SKINNER, R.H., NELSON, C.J. Elongation of the grass leaf and its relationship to the phyllochron. Crop Science, Madison, v.35, p.4-10, 1995.

THIMIJAN, R.W., HEINS, R.D. Photometric, radiometric, and quantum light units of measure: a review of procedures for interconversion. Hort Science, St. Joseph, v.18, p.818-822, 1983.

VAN DEN BOOGAARD, R. ALEWIJNSE, D, VENEKLAAS, E.J., et al. Growth and water-use efficiency of 10 Triticum aestivum cultivars at different water availability in relation to allocation of biomass. Plant, Cell and Environmental, Oxford, v.20, p.200-210, 1997.

WOBETO, C. Padrão de afilhamento, sobrevivência de afilhos e suas relações com o rendimento de grãos em trigo. Porto Alegre, 1994. 102p. Dissertação (Mestrado em Fitotecnia) - Programa de Pós-graduação em Fitotecnia, Universidade Federal do Rio Grande do Sul, 1994. 